\title{
MCM7 amplification and overexpression promote cell proliferation, colony formation and migration in esophageal squamous cell carcinoma by activating the AKT1/mTOR signaling pathway
}

\author{
YUN-TAN QIU*, WEN-JUN WANG* ${ }^{*}$, BING ZHANG* ${ }^{*}$ LI-LI MEI and ZHI-ZHOU SHI \\ Faculty of Medicine, Kunming University of Science and Technology, Kunming, Yunnan 650500, P.R. China
}

Received October 28, 2016; Accepted April 24, 2017

DOI: $10.3892 /$ or.2017.5614

\begin{abstract}
The roles and mechanisms of mini-chromosome maintenance complex component 7 (MCM7) amplification and overexpression in esophageal carcinogenesis were investigated. By analyzing the TCGA datasets, we found that MCM7 was amplified in approximately $12 \%$ of esophageal squamous cell carcinomas (ESCCs), and in more than $4 \%$ of head and neck squamous cell carcinomas and stomach carcinomas. Overexpression of MCM7 was further verified in three independent GEO datasets of esophageal cancer. Knockdown of MCM7 using two siRNAs significantly inhibited cell proliferation, colony formation and migration of KYSE510 and EC9706 cells in vitro. Noteworthy, we further found that silencing of MCM7 suppressed the phosphorylation of AKT1 and mTOR both in KYSE510 and EC9706 cells, and reduced the cell cycle regulatory proteins cyclin D1, cyclin E2 and CDK2. Taken together, our findings suggested that MCM7 promoted tumor cell proliferation, colony formation and migration of ESCC cells via activating AKT1/mTOR signaling pathway.
\end{abstract}

\section{Introduction}

Esophageal cancer is the sixth leading cause of cancer-related death in the world and the fourth leading cause of cancerrelated death in China (1). There are two types of esophageal cancer, squamous cell carcinoma (SCC) and adenocarcinoma (AC), and most Chinese esophageal cancers are ESCCs (2). Although diagnostic methods and cancer treatments have

Correspondence to: Professor Zhi-Zhou Shi, Faculty of Medicine, Kunming University of Science and Technology, 727 Jingming South Road, Kunming, Yunnan 650500, P.R. China

E-mail: zhizhoushi@126.com

*Contributed equally

Key words: MCM7, proliferation, migration, AKT1, mTOR improved in recent years, the prognosis is still poor because of widespread lymph node metastasis and relatively frequent distant metastasis. Therefore, understanding the mechanism of esophageal carcinogenesis will lay the foundations for improving clinical management and outcomes.

Mini-chromosome maintenance protein complex (MCM) is a eukaryotic DNA helicase complex required for initiation of DNA replication. The MCM proteins include six members, MCM2 to MCM7, and are considered as molecular markers of proliferation in several types of cancer (3-6). MCM7 is a critical component of DNA replication licensing complex, and is overexpressed in multiple human malignancies including hepatocellular carcinoma, head and neck squamous cell carcinoma, prostate carcinoma and esophageal squamous cell carcinoma (7-10). Kim et al found that upregulation of MCM7 was associated with cisplatin resistance in bladder cancer (11). In liver cancer MHCC-97 cells, silence of MCM7 dramatically reduced the cell proliferation, migration, invasion and increased the apoptotic cells (12).

Our previous and other studies found that MCM7 was amplified and overexpressed in ESCC, and overexpression of MCM7 was significantly linked with poor prognosis $(7,13,14)$, however the roles and mechanisms of MCM7 amplification and overexpression in ESCC were largely unclear. In the present study, we revealed that MCM7 promoted tumor cell proliferation, colony formation and migration of ESCC cells via inhibiting the AKT1/mTOR signaling pathway.

\section{Materials and methods}

TCGA and GEO datasets. Genomic and expression data of MCM7 are publically available from the Cancer Genome Atlas and the NCBI Gene Expression Omnibus. The copy number alterations and mutations of TCGA datasets were analyzed by Cbioportal (www.cbioportal.org). For GSE datasets of GSE20347, GSE38129 and GSE29001, the mRNA expression levels are detected by microarray, and the difference of MCM7 between ESCC tissues and paracancerous tissues was analyzed using the paired t-test by SPSS 19.

Cell culture. The human esophageal cancer cell lines were supplied by Peking Union Medical College and Chinese 


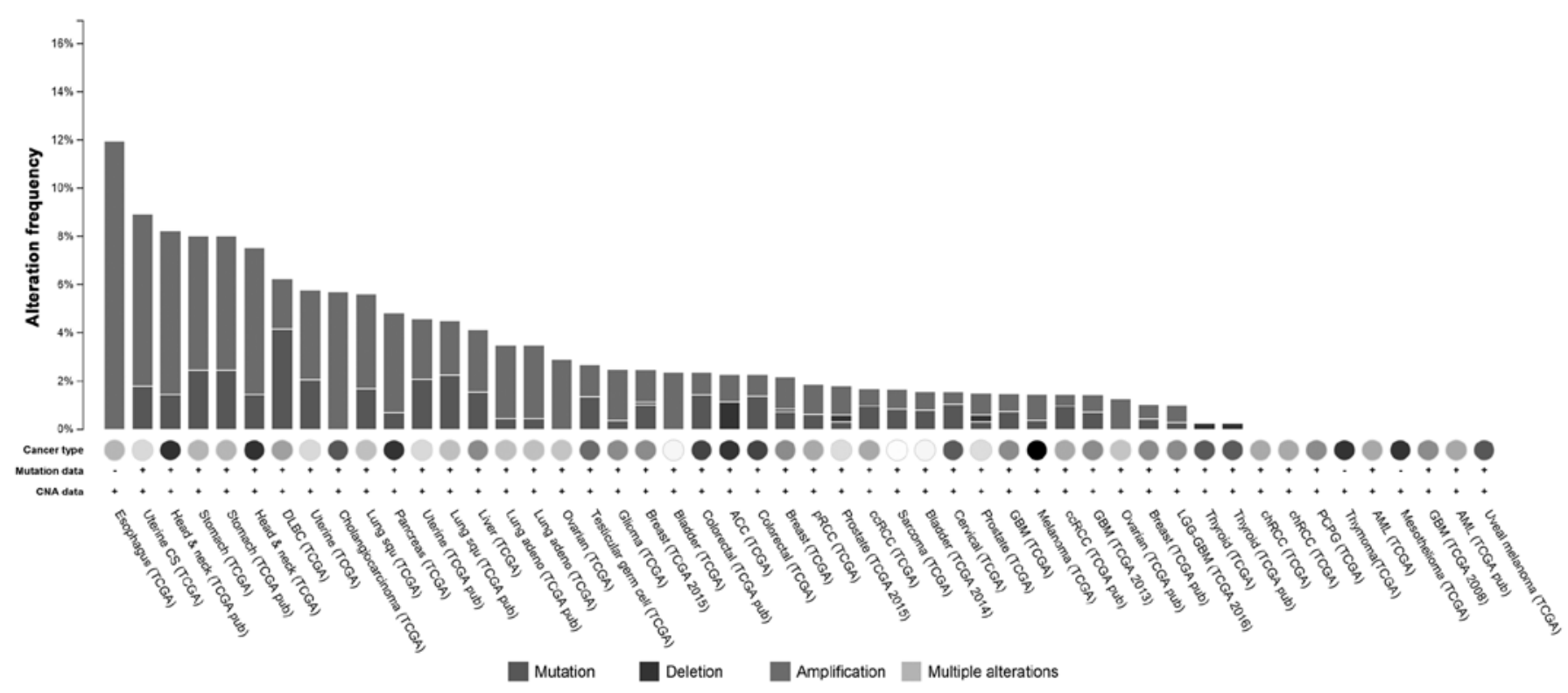

Figure 1. Amplification of MCM7 in many types of cancer in TCGA data. The figure was ploted using Cbioportal website and depicted the genomic aberration frequency. Panel shows the frequency and type of alterations for each analyzed study. The x-axis shows the types of cancer, availability of mutation and copy number variation data, and the study abbreviation.

Academy of Medical Sciences. All cell lines were cultured in RPMI-1640 medium with $10 \%$ fetal bovine serum, $100 \mathrm{U} / \mathrm{ml}$ penicillin and $100 \mathrm{~g} / \mathrm{ml}$ streptomycin at $37^{\circ} \mathrm{C}$ in a humidified incubator containing $5 \%$ carbon dioxide.

siRNAs and transfection. The synthetic negative control siRNA, MCM7 siRNA-1 and MCM7 siRNA-2 were purchased from Shanghai Gene Pharma Co. Ltd. The ESCC cell lines were transiently transfected using Lipofectamine ${ }^{\circledR} 2000$ Transfection Reagent from Invitrogen according to the manufacturer's protocol. The sequences of negative control siRNA, MCM7 siRNA-1 and MCM7 siRNA-2 were as follows: Negative control siRNA: 5'-UUCUCCGAACGUGUCACGUTT-3'; MCM7 siRNA-1: 5'-ATCGGATTGTGAAGATGAA-3'; MCM7 siRNA-2: 5'-AAGAUGUCCUGGACGUUUACA-3'.

Total RNA extraction and real-time PCR assay. Total RNA was isolated from cancer cells using the RNeasy mini kit as described by the manufacturer (Qiagen, Hilden, Germany) and used for Real-time PCR assay.

Real-time PCR was used to detect the mRNA expression levels of cyclin D1, cyclin E2 and CDK2. The PCR reactions were performed in a total volume of $20 \mu \mathrm{l}$, including $10 \mu \mathrm{l}$ of 2X Power SYBR ${ }^{\circledR}$ Green PCR Master Mix (Applied Biosystems, Warrington, UK), $2 \mu \mathrm{l}$ of cDNA (5 ng/ $\mu \mathrm{l})$ and $1 \mu \mathrm{l}$ of primer mix (10 $\mu \mathrm{M}$ each). PCR amplification and detection were performed in a LightCycler 480 II (Roche Applied Science) as follows: an initial denaturation at $95^{\circ} \mathrm{C}$ for $10 \mathrm{~min}$; 40 cycles at $95^{\circ} \mathrm{C}$ for $15 \mathrm{sec}$ and $60^{\circ} \mathrm{C}$ for $1 \mathrm{~min}$. The relative gene expression was calculated using the comparative CT method. The gene expression of the target gene were normalized to an endogenous reference (GAPDH), and relative to the calibrator were given by the formula $2-\Delta \Delta \mathrm{Ct}$. $\Delta \mathrm{CT}$ was calculated by subtracting the average GAPDH CT from the average CT of the gene of interest. The ratio defines the level of relative expression of the target gene to that of GAPDH.
The primers were as follows: Cyclin D1 forward primer, 5'-ACGCTTACCTCAACCATCCTG-3'; Cyclin D1 reverse primer, 5'-GGCCTCTCGATACACACAACA-3'; Cyclin E2 forward primer, 5'-GCCCGGCCTATATATTGGGTT-3'; Cyclin E2 reverse primer, 5'-AACGGCTACTTCGTCT TGACA-3'; CDK2 forward primer, 5'-TCTTTGCTGAG ATGGTGACTCG-3'; CDK2 reverse primer, 5'-TCTTCA TCCAGGGGAGGTACA-3'; GAPDH forward primer, 5'-AAATCCCATCACCATCTTCCAG-3'; GAPDH reverse primer, 5'-GAGTCCTTCCACGATACCAAAGTTG-3'.

Western blot assay. Cells were lysed in the lysis buffer $(20 \mathrm{mM}$ Tris, 2 mM EDTA, 50 mM 2-mecaptoethanol, 10\% glycerol, $\mathrm{pH}$ 7.4). The homogenates were placed on ice for $30 \mathrm{~min}$ and centrifuged at $12,000 \mathrm{x} \mathrm{g}$ for $15 \mathrm{~min}$ at $4^{\circ} \mathrm{C}$. Afterward, the protein concentrations of the lysates were determined using a Protein Assay kit (Bio-Rad, Richmond, CA, USA). Equal amounts of total proteins were loaded onto a $10 \%$ gradient polyacrylamide gel, electrophoretically transferred to polyvinylidene difluoride membrane, and then blocked with $10 \%$ non-fat milk for $2 \mathrm{~h}$ at room temperature. The membranes were incubated with specific primary antibodies overnight at $4^{\circ} \mathrm{C}$ and probed with corresponding secondary antibodies for $1 \mathrm{~h}$ at room temperature. The protein bands were visualized using ECL Blotting Detection Reagents (Applygen, Beijing, China). The primary antibodies were as follows: MCM7 (1:1000; Santa Cruz Biotechnology, Santa Cruz, CA, USA), p-AKT1 (1:1000; Santa Cruz Biotechnology), AKT1 (1:1000; Santa Cruz Biotechnology), p-mTOR (1:1000; Santa Cruz Biotechnology), mTOR (1:1000; Santa Cruz Biotechnology) and $\beta$-actin (1:5000; Santa Cruz Biotechnology).

Cell proliferation assay. The Cell Counting Kit-8 (Dojindo Laboratories, Kumamoto, Japan) was performed to quantify the proliferation of KYSE510 and EC9706 cells. Cells were cultured at 1000/well in 96-well plates. After incubated for 24, 
A

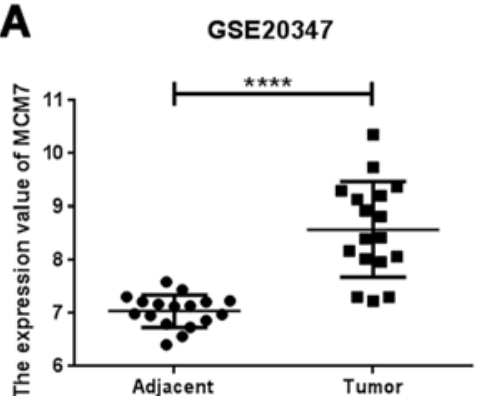

B

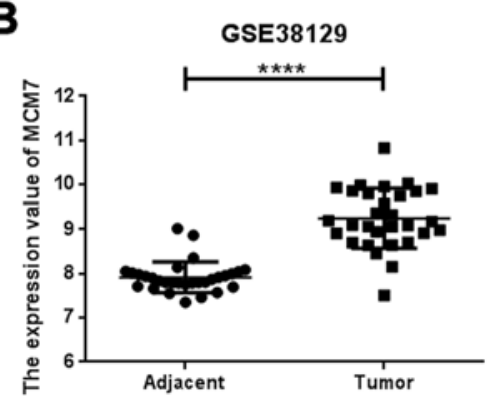

C

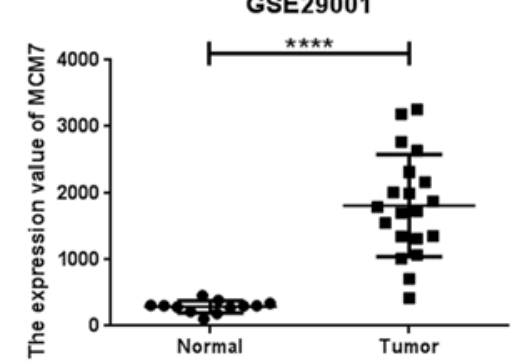

Figure 2. MCM7 is overexpressed in ESCC by analyzing GSE datasets. The differences of expression levels of MCM7 in tumor tissues and para-cancerous tissues in the datasets of GSE20347 (A), GSE38129 (B) and GSE29001 (C) were analyzed by using Student's two-tailed t-test. " $\mathrm{P}<0.05,{ }^{, * *} \mathrm{P}<0.01,{ }^{* * * *} \mathrm{P}<0.001$ and ${ }^{* * * *} \mathrm{P}<0.0001$.

A

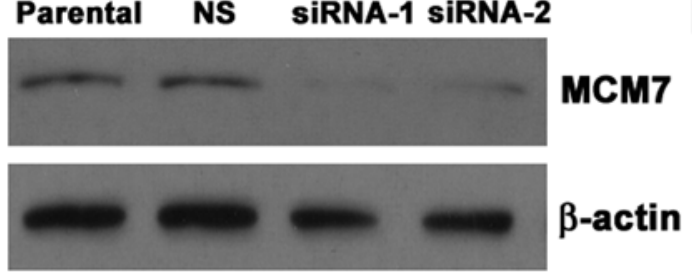

KYSE510

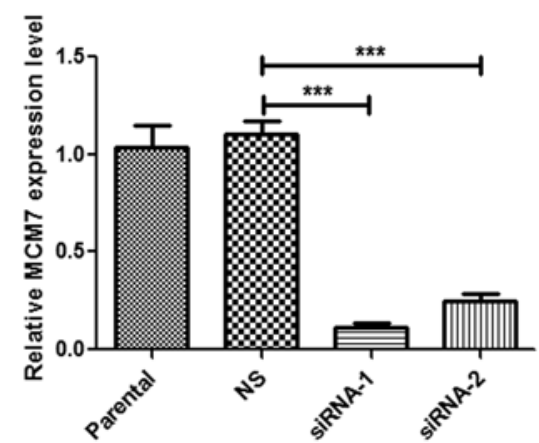

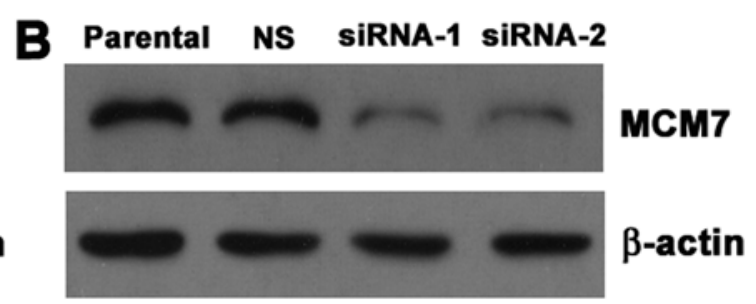

EC9706

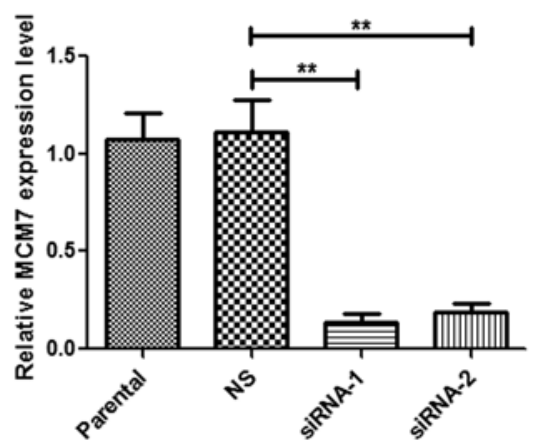

Figure 3. The RNAi efficiency of siRNAs targeting MCM7 in KYSE510 and EC9706 cells. The RNAi efficiency of siRNA-1 and siRNA-2 targeting MCM7 in KYSE510 (A) and EC9706 (B) cells was detected by western blot assay. Data are presented as mean \pm SEM of $n=3$ independent experiments. The differences between MCM7 siRNA group and negative control group were analyzed by using Student's two-tailed t-test. ${ }^{*} \mathrm{P}<0.05,{ }^{* *} \mathrm{P}<0.01,{ }^{* * * *} \mathrm{P}<0.001$ and ${ }^{* * * *} \mathrm{P}<0.0001$.

$48,72,84,96$, or $120 \mathrm{~h}, 10 \mu \mathrm{l}$ of CCK-8 was added to each well and incubated for $1 \mathrm{~h}$. The absorbance of each well was read at $450 \mathrm{~nm}$. Three independent experiments were performed.

Colony formation assay. For each group, 5000 cells were plated in 6-well plate. After cultured for 10 days, the cells were washed with PBS, fixed with methanol and $0.1 \%$ crystal violet. Then, the colonies were counted and photographed. Three independent experiments were performed.

Transwell assay. The migration assay was performed on Transwell plates. For cell migration assay, $1 \times 10^{5}$ cells were seeded on a polycarbonate membrane insert in a Transwell apparatus (Costar, Cambridge, MA, USA) and cultured in RPMI-1640 without serum. RPMI-1640 containing 20\% fetal bovine serum was added to the lower chamber. After incubation for $24 \mathrm{~h}$ at $37^{\circ} \mathrm{C}$ in a $\mathrm{CO}_{2}$ incubator, the insert was washed with PBS, and cells on the top surface of the insert were removed by wiping with a cotton swab. Cells that migrated to the bottom surface of the insert were fixed with methanol, stained with $0.4 \%$ crystal violet, and counted in five random fields at $\mathrm{x} 200$.

Statistical analysis. The data were analyzed by Student's t-test and one-way analysis of variance using the SPSS and Graphpad Prism 5.0. $\mathrm{P}<0.05$ was considered to indicate a statistical significant difference.

\section{Results}

MCM7 is amplified and overexpressed in many types of cancer including ESCC. The datasets of The Cancer Genome Atlas (TCGA) showed that MCM7 was amplified in approximately $12 \%$ of ESCCs, and in $>4 \%$ of head and neck squamous cell carcinomas and stomach carcinomas, and the amplification was the dominant form of changes in DNA level; however in diffuse large B-cell lymphoma (DLBC), mutation was more frequent than amplification (Fig. 1). MCM7 was overexpressed 

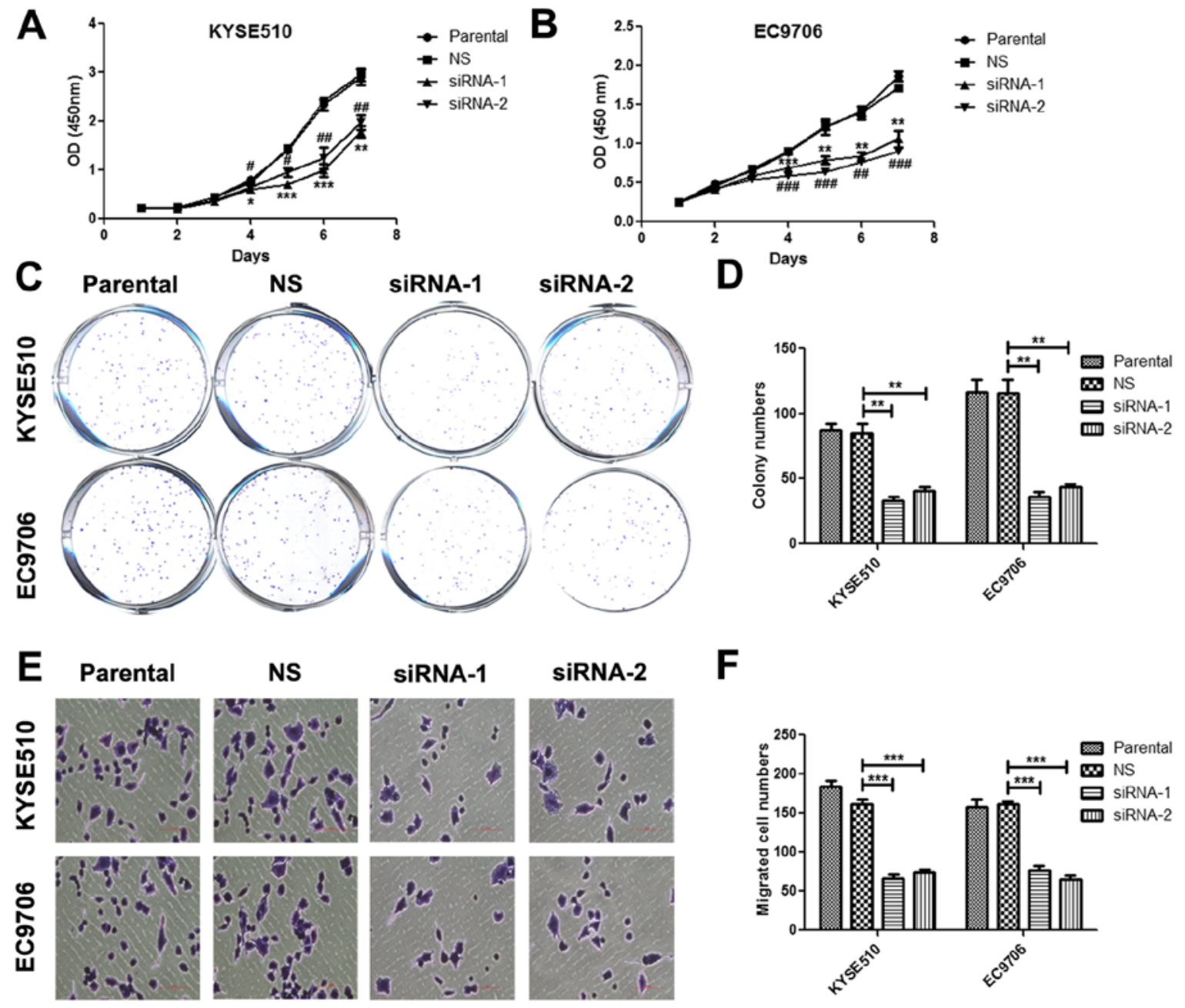

Figure 4. Knockdown of MCM7 suppresses cell proliferation, colony formation and migration of KYSE510 and EC9706 cells. Effects of MCM7 siRNAs on the cell proliferation of KYSE510 (A) and EC9706 (B) cells were detected by Cell Counting Kit-8. (C and D) Effects of MCM7 siRNAs on the colony formation of KYSE510 and EC9706 cells was measured by crystal violet staining. (E and F) Effects of MCM7 siRNAs on the migration of KYSE510 and EC9706 cells were detected by Transwell assay. Representative images are shown. Data are presented as mean \pm SEM of $n=3$ independent experiments. The differences between MCM7 siRNAs group and negative control group were analyzed by using Student's two-tailed t-test. ${ }^{*} \mathrm{P}<0.05,{ }^{* * *} \mathrm{P}<0.01,{ }^{* * *} \mathrm{P}<0.001$ and ${ }^{* * * *} \mathrm{P}<0.0001$.

in ESCC tissues in the datasets of GSE20347, GSE38129 and GSE29001 (Fig. 2).

Knockdown of MCM7 suppresses the proliferation, colony formation and migration of ESCC cells. In order to explore the tumorigenic roles and mechanisms of MCM7 in esophageal carcinogenesis, we selected cell lines KYSE510 and EC9706 with higher MCM7 expression for further study.

siRNAs were used to knock down the MCM7 expression in KYSE510 and EC9706 cells, and the RNAi efficiency was determined by western blot assay (Fig. 3A and B). Using CCK-8 proliferation assay, we found that silence of MCM7 significantly inhibited cell proliferation compared with nonsilencing group, and there was significant suppression at days 4, 5, 6 and 7 both in KYSE510 and EC9706 cells (Fig. 4A and $\mathrm{B})$. In colony formation assay, we observed that colony numbers were significantly lower in MCM7 siRNA-1 and siRNA-2 transfected cells than in the control group both in KYSE510 and EC9706 cells (Fig. 4C and D). By Transwell assay, we revealed that silence of MCM7 significantly inhibited the migration of KYSE510 and EC9706 cells (Fig. 4E and F).
Knockdown of MCM7 suppressed the AKT1/mTOR signaling pathway in ESCC. Many studies showed that activated AKT1/mTOR signaling pathway promoted cancer cell proliferation, epithelial-mesenchymal transition (EMT), tumor metastasis and invasion (15-20). Noteworthy, our study revealed that silencing MCM7 significantly inhibited the phosphorylation of AKT1 and mTOR (Fig. 5). In addition, knockdown of MCM7 reduced the cell cycle regulatory genes cyclin D1, cyclin E2 and CDK2 in mRNA expression levels (Fig. 6). These results indicated that MCM7 amplification and overexpression promoted cell proliferation, colony formation and migration via activating the AKT1/mTOR signaling pathway.

\section{Discussion}

Genomic aberrations can contribute to carcinogenesis and tumor progression. In the past decades, the understanding of molecular pathogenesis of ESCC has developed, but is still limited. Thus, elucidation of the mechanism of esophageal carcinogenesis was very important for tumor diagnosis and 


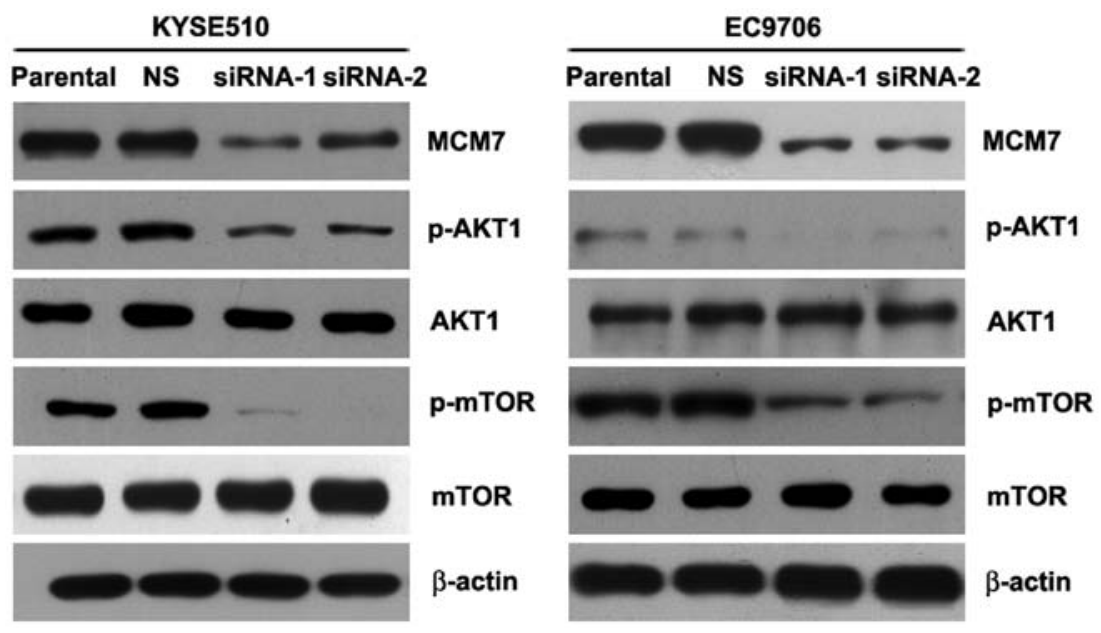

Figure 5. Knockdown of MCM7 inhibits phosphorylation of AKT1 and mTOR in KYSE510 and EC9706 cells. Protein levels of MCM7, p-AKT1, AKT1, p-mTOR, mTOR and $\beta$-actin in KYSE510 and EC9706 cells. Cells were transfected with negative control siRNA, MCM7 siRNA-1 and siRNA-2 for 48 h. All the protein levels were determined by western blotting. The experiment was repeated three times.
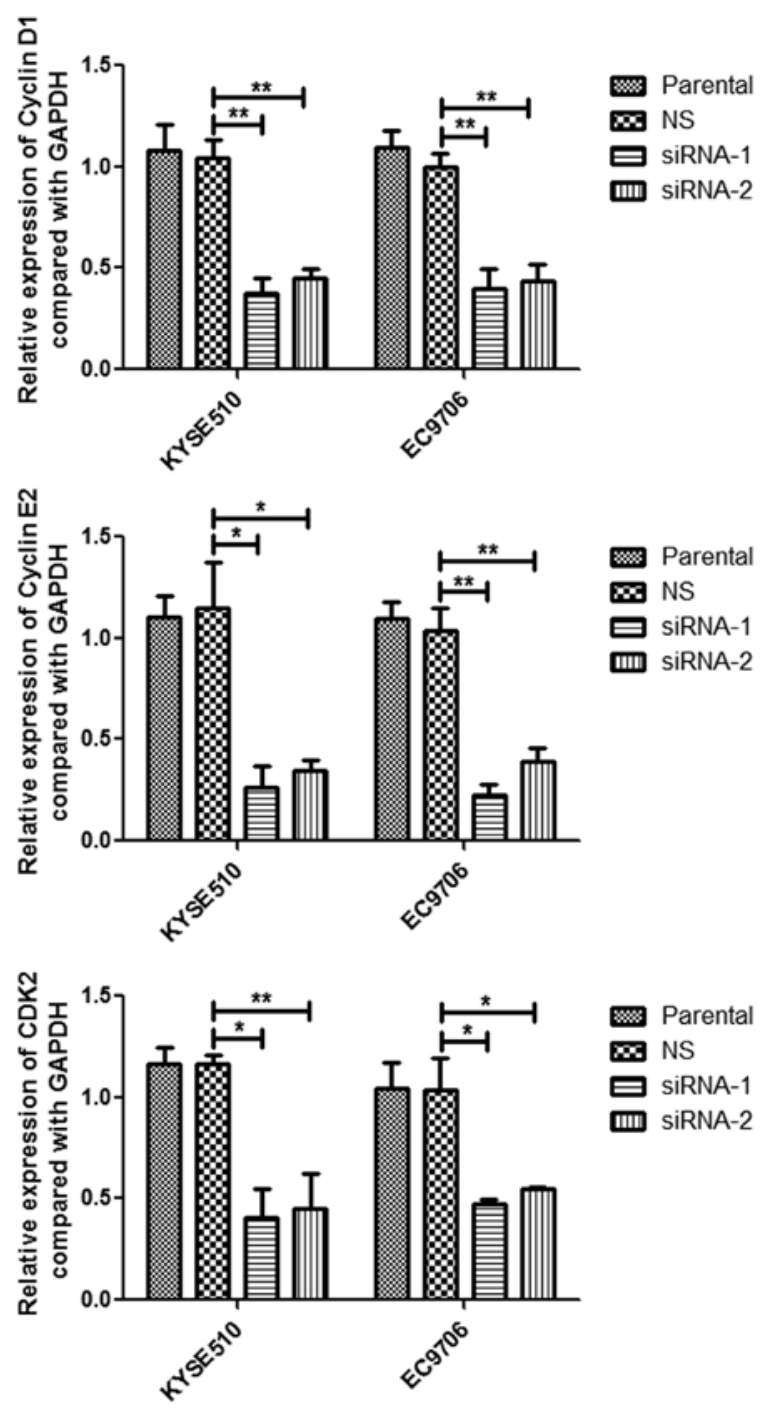

Figure 6. Knockdown of MCM7 reduces the mRNA expression levels of cyclin D1, cyclin E2 and CDK2. Cells were transfected with negative control siRNA, MCM7 siRNA-1 and siRNA-2 for $48 \mathrm{~h}$. All the mRNA levels were determined by real-time PCR normalized with GAPDH. Data are presented as mean \pm SEM, and the differences between MCM7 siRNA group and negative control group were analyzed by using Student's two-tailed t-test. ${ }^{*} \mathrm{P}<0.05$, ${ }^{* * *} \mathrm{P}<0.01,{ }^{* * * *} \mathrm{P}<0.001$ and ${ }^{* * * * *} \mathrm{P}<0.0001$. therapy. Recently, it was shown that MCM proteins were overexpressed in several types of tumors, and high expression levels of MCM proteins including MCM2, MCM3 and MCM7 were positively correlated with $\mathrm{Ki}-67$ positive staining in Laryngeal squamous cell carcinoma (LSCC) (5).

MCM7 is a critical DNA replication licensing factor in both yeast and xenopus oocytes, and serves as a co-transcriptional and co-translational enhancing factor of androgen receptor, which regulates cell growth and proliferation (21). Increased MCM7 expression is common in various human cancers including esophageal squamous cell carcinoma, prostate cancer and pancreatic cancer $(7,10,22,23)$, and MCM7 has been considered as a tumorigenesis-related gene (24). In pituitary adenoma, diffuse-type primary gastric adenocarcinoma and colorectal cancer, the patients with MCM7 overexpression had a shorter recurrence/progression-free survival respectively $(25,26)$. MCM7 promotes tumor cell proliferation and invasion in papillary urothelial neoplasia and liver cancer (27), and depletion of MCM7 inhibits glioblastoma multiforme tumor growth in vivo (28). In ESCC, G9a and MCM7 overexpression levels were correlated with poor prognosis (7), however, the roles and mechanisms of MCM7 amplification and overexpression in ESCC were largely unknown. Our results showed that MCM7 promoted tumor cell proliferation, colony formation and migration of ESCC cells.

AKT, a serine/threonine kinase, has a wide tissue distribution and regulates many processes including cell metabolism, proliferation, survival and tumor growth (29). Notably, AKT has been considered as a critical oncogene, and it can activate downstream signaling pathways through phosphorylation of a plethora of AKT substrates (30). In recent studies, the phosphorylation of AKT was shown correlated with poor prognosis in ESCC $(31,32)$. AKT was responsible for the cisplatin resistance, and could promote metastasis of ESCC by targeting epithelial-mesenchymal transition (33-35). mTOR activation was able to also prcomote the cell proliferation and tumor progression of ESCC $(36,37)$. However, the direct relationship between AKT/mTOR and MCM7 has not been reported. Our findings further revealed that knockdown 
of MCM7 significantly inhibited the phosphorylation of AKT and mTOR.

In summary, our data revealed that MCM7 promoted tumor cell proliferation, colony formation and migration via activating the AKT1/mTOR signaling pathway. Future studies should focus on how MCM7 regulates the AKT1/ mTOR signaling pathway, and explore the antitumor activity of MCM7 silencing in an animal model.

\section{Acknowledgements}

This study was supported by the National Natural Science Foundation of China (no. 81460425) and the Yunnan Provincial Research Foundation for Basic Research, China (no. 2013FD012) and Foundation for the Talents of Kunming University of Science and Technology (no. KKSY201226099).

\section{References}

1. Chen W, Zheng R, Zuo T, Zeng H, Zhang S and He J: National cancer incidence and mortality in China, 2012. Chin J Cancer Res 28: 1-11, 2016.

2. He YT, Hou J, Chen ZF, Qiao CY, Song GH, Meng FS, Jin HX and Chen $\mathrm{C}$ : Decrease in the esophageal cancer incidence rate in mountainous but not level parts of Cixian County, China, over 29 years. Asian Pac J Cancer Prev 6: 510-514, 2005.

3. Chang CC, Huang CC, Yang SH, Chien CC, Lee CL and Huang CJ: Data on clinical significance of GAS2 in colorectal cancer cells. Data Brief 8: 82-86, 2016.

4. Juríková M, Danihel L', Polák S and Varga I: Ki67, PCNA, and MCM proteins: Markers of proliferation in the diagnosis of breast cancer. Acta Histochem 118: 544-552, 2016.

5. Nowinska K, Chmielewska M, Piotrowska A, Pula B Pastuszewski W, Krecicki T, Podhorska-Okołow M, Zabel M and Dziegiel P: Correlation between levels of expression of minichromosome maintenance proteins, Ki-67 proliferation antigen and metallothionein $\mathrm{I} / \mathrm{II}$ in laryngeal squamous cell cancer. Int J Oncol 48: 635-645, 2016.

6. Gann PH, Deaton RJ, Rueter EE, van Breemen RB, Nonn L, Macias V, Han M and Ananthanarayanan V: A phase II randomized trial of lycopene-rich tomato extract among men with high-grade prostatic intraepithelial neoplasia. Nutr Cancer 67: 1104-1112, 2015.

7. Zhong X, Chen X, Guan X, Zhang H, Ma Y, Zhang S, Wang E, Zhang L and Han Y: Overexpression of G9a and MCM7 in oesophageal squamous cell carcinoma is associated with poor prognosis. Histopathology 66: 192-200, 2015.

8. Zhou YM, Zhang XF, Cao L, Li B, Sui CJ, Li YM and Yin ZF: MCM7 expression predicts post-operative prognosis for hepatocellular carcinoma. Liver Int 32: 1505-1509, 2012.

9. Honeycutt KA, Chen Z, Koster MI, Miers M, Nuchtern J, Hicks J, Roop DR and Shohet JM: Deregulated minichromosomal maintenance protein MCM7 contributes to oncogene driven tumorigenesis. Oncogene 25: 4027-4032, 2006.

10. Ren B, Yu G, Tseng GC, Cieply K, Gavel T, Nelson J, Michalopoulos G, Yu YP and Luo JH: MCM7 amplification and overexpression are associated with prostate cancer progression. Oncogene 25: 1090-1098, 2006.

11. Kim SH, Ho JN, Jin H, Lee SC, Lee SE, Hong SK, Lee JW Lee ES and Byun SS: Upregulated expression of BCL2, MCM7, and CCNE1 indicate cisplatin-resistance in the set of two human bladder cancer cell lines: T24 cisplatin sensitive and T24R2 cisplatin resistant bladder cancer cell lines. Investig Clin Urol 57: 63-72, 2016.

12. Liu J, Tian L, Chen BA and Xia JR: Biological effects of lentivirus-mediated silencing of minichromosome maintenance protein 7 with shRNA on the liver cancer MHCC-97H cells. Int J Clin Exp Med 8: 8433-8441, 2015.

13. Kan T, Sato F, Ito T, Matsumura N, David S, Cheng Y, Agarwal R, Paun BC, Jin Z, Olaru AV, et al: The miR-106b-25 polycistron, activated by genomic amplification, functions as an oncogene by suppressing p21 and Bim. Gastroenterology 136: 1689-1700, 2009.
14. Shi ZZ, Shang L, Jiang YY, Hao JJ, Zhang Y, Zhang TT, Lin DC, Liu SG, Wang BS, Gong T, et al: Consistent and differential genetic aberrations between esophageal dysplasia and squamous cell carcinoma detected by array comparative genomic hybridization. Clin Cancer Res 19: 5867-5878, 2013.

15. Leu WJ, Swain ShP, Chan SH, Hsu JL, Liu SP, Chan ML, Yu CC, Hsu LC, Chou YL, Chang WL, et al: Non-immunosuppressive triazole-based small molecule induces anticancer activity against human hormone-refractory prostate cancers: The role in inhibition of PI3K/AKT/mTOR and c-Myc signaling pathways. Oncotarget 7: 76995-77009, 2016.

16. Liu L, Pan Y, Song Y, Su X, Ke R, Yang L, Gao L and Li M: Activation of AMPK $\alpha 2$ inhibits airway smooth muscle cells proliferation. Eur J Pharmacol 791: 235-243, 2016.

17. Moravčík R, Stebelová K, Boháč A and Zeman M: Inhibition of VEGF mediated post receptor signalling pathways by recently developed tyrosine kinase inhibitor in comparison with sunitinib. Gen Physiol Biophys 35: 511-514, 2016.

18. Divine LM, Nguyen MR, Meller E, Desai RA, Arif B, Rankin EB, Bligard KH, Meyerson C, Hagemann IS, Massad M, et al: AXL modulates extracellular matrix protein expression and is essential for invasion and metastasis in endometrial cancer. Oncotarget 7 : 77291-77305, 2016.

19. Yang Y, Gao Z, Ma Y, Teng H, Liu Z, Wei H, Lu Y, Cheng X, Hou L and Zou X: Fucoidan inhibits lymphangiogenesis by downregulating the expression of VEGFR3 and PROX1 in human lymphatic endothelial cells. Oncotarget 7: 38025-38035, 2016.

20. Wei L, Li K, Pang X, Guo B, Su M, Huang Y, Wang N, Ji F, Zhong C, Yang J, et al: Leptin promotes epithelial-mesenchymal transition of breast cancer via the upregulation of pyruvate kinase M2. J Exp Clin Cancer Res 35: 166, 2016.

21. Shi YK, Yu YP, Zhu ZH, Han YC, Ren B, Nelson JB and Luo JH: MCM7 interacts with androgen receptor. Am J Pathol 173: 1758-1767, 2008.

22. Lau KM, Chan QK, Pang JC, Li KK, Yeung WW, Chung NY, Lui PC, Tam YS, Li HM, Zhou L, et al: Minichromosome maintenance proteins 2, 3 and 7 in medulloblastoma: Overexpression and involvement in regulation of cell migration and invasion. Oncogene 29: 5475-5489, 2010

23. Liang JW, Shi ZZ, Shen TY, Che X, Wang Z, Shi SS, Xu X, Cai Y, Zhao P, Wang CF, et al: Identification of genomic alterations in pancreatic cancer using array-based comparative genomic hybridization. PLoS One 9: e114616, 2014.

24. Huber AR, Tan D, Sun J, Dean D, Wu T and Zhou Z: High expression of carbonic anhydrase IX is significantly associated with glandular lesions in gastroesophageal junction and with tumorigenesis markers BMI1, MCM4 and MCM7. BMC Gastroenterol 15: 80, 2015.

25. Coli A, Asa SL, Fadda G, Scannone D, Chiloiro S, De Marinis L, Lauretti L, Ranelletti FO and Lauriola L: Minichromosome maintenance protein 7 as prognostic marker of tumor aggressiveness in pituitary adenoma patients. Eur J Endocrinol 174: 307-314, 2016.

26. Ishibashi Y, Kinugasa T, Akagi Y, Ohchi T, Gotanda Y, Tanaka N, Fujino S, Yuge K, Kibe S, Yoshida N, et al: Minichromosome maintenance protein 7 is a risk factor for recurrence in patients with Dukes C colorectal cancer. Anticancer Res 34: 4569-4575, 2014.

27. Guan B, Wang X, Yang J, Zhou C and Meng Y: Minichromosome maintenance complex component 7 has an important role in the invasion of papillary urothelial neoplasia. Oncol Lett 10: 946-950, 2015

28. Erkan EP, Ströbel T, Lewandrowski G, Tannous B, Madlener S, Czech T, Saydam N and Saydam O: Depletion of minichromosome maintenance protein 7 inhibits glioblastoma multiforme tumor growth in vivo. Oncogene 33: 4778-4785, 2014.

29. Vivanco I and Sawyers CL: The phosphatidylinositol 3-Kinase AKT pathway in human cancer. Nat Rev Cancer 2: 489-501, 2002.

30. Hers I, Vincent EE and Tavaré JM: Akt signalling in health and disease. Cell Signal 23: 1515-1527, 2011.

31. Zhu Z, Yu W, Fu X, Sun M, Wei Q, Li D, Chen H, Xiang J, Li H, Zhang Y, et al: Phosphorylated AKT1 is associated with poor prognosis in esophageal squamous cell carcinoma. J Exp Clin Cancer Res 34: 95, 2015.

32. Kircher DA, Arave RA, Cho JH and Holmen SL: Melanoma metastases caught in the AKT. Mol Cell Oncol 3: e1128516, 2016. 
33. Shan B, Man H, Liu J, Wang L, Zhu T, Ma M, Xv Z, Chen X, Yang $X$ and Li P: TIM-3 promotes the metastasis of esophageal squamous cell carcinoma by targeting epithelial-mesenchymal transition via the Akt/GSK-3 $\beta /$ Snail signaling pathway. Oncol Rep 36: 1551-1561, 2016.

34. Liu T, Li R, Zhao H, Deng J, Long Y, Shuai MT, Li Q, Gu H, Chen YQ and Leng AM: eIF4E promotes tumorigenesis and modulates chemosensitivity to cisplatin in esophageal squamous cell carcinoma. Oncotarget 7: 66851-66864, 2016.

35. Li DJ, Shi M and Wang Z: RUNX3 reverses cisplatin resistance in esophageal squamous cell carcinoma via suppression of the protein kinase B pathway. Thorac Cancer 7: 570-580, 2016.
36. Ji YM, Zhou XF, Zhang J, Zheng X, Li SB, Wei ZQ, Liu T, Cheng DL, Liu P, Song K, et al: DEPTOR suppresses the progression of esophageal squamous cell carcinoma and predicts poor prognosis. Oncotarget 7: 14188-14198, 2016.

37. Zhang W, Lei C, Fan J and Wang J: miR-18a promotes cell proliferation of esophageal squamous cell carcinoma cells by increasing cylin D1 via regulating PTEN-PI3K-AKT-mTOR signaling axis. Biochem Biophys Res Commun 477: 144-149, 2016. 